\title{
EMOTIONAL LABOR STRATEGY AND JOB SATISFACTION: A CHINESE PERSPECTIVE
}

\author{
XUAN JIANG \\ Yanbian University \\ ZHOU JIANG \\ Macquarie University \\ DONG SOO PARK \\ Yeungnam University
}

\begin{abstract}
We examined the relationship between emotional labor strategy (ELS) and job satisfaction (JS), and the moderating effects of job characteristics on this relationship, based on data collected from 291 supermarket employees. Results showed that the 2 types of ELS, surface acting and deep acting, were negatively and positively related to JS, respectively. In general, job characteristics were found to moderate the relationship between ELS and JS.
\end{abstract}

Keywords: emotional labor strategy, surface acting, deep acting, job satisfaction, job characteristics.

Emotional labor has become a popular domain of employment psychology. Hochschild (1983) defined emotional labor as "the management of feeling to create a publicly observable facial and bodily display" (p. 7). Hochschild proposed that to complete tasks employees not only exert cognitive and physical effort (i.e., mental and manual labor), but also control and manage their emotions and expressions (i.e., emotional labor). It is crucial for employees, especially in the service industry, to treat customers cordially and to provide high-quality service to accommodate customers' needs and expectations (Hochschild, 1983; Rafaeli \& Sutton, 1987; Van Maanen \& Kunda, 1989). An increasing number

Xuan Jiang, Department of Business Administration, School of Economics and Management, Yanbian University; Zhou Jiang, Faculty of Business and Economics, Macquarie University; Dong Soo Park, School of Business Administration, Yeungnam University.

Correspondence concerning this article should be addressed to: Dong Soo Park, School of Business Administration, College of Business and Economics, Yeungnam University, 280 Daehak-ro, Gyeongsan, Gyeongbuk, Republic of Korea. Email: dspark@ynu.ac.kr 
of organizations try to promote employees' positive emotional expressions. Consequently, employees are encouraged to internalize their emotions and expressions to meet work requirements (Wharton \& Erickson, 1993). However, as employees may possess different emotional abilities, the influences of these emotional tendencies on their reactions at work may be different. To our knowledge, the mechanisms affecting these influences have been examined in only a few studies. These influences may also vary according to individual job characteristics. To explore whether or not this conjecture is true in China's service industry, in this context we examined the relationship between employees' emotional labor strategy (ELS) and job satisfaction (JS), the most intensively investigated variable in organizational studies (Rainey, 2009), and the moderating effects of job characteristics on this relationship.

\section{Literature Review}

\section{Emotional Labor Strategy}

According to Hochschild (1979, 1983), a service provider performs emotional labor using one of two strategies: surface acting (SA) or deep acting (DA). SA involves employees complying with organizational display rules to modify their outward emotional display without changing their inner feelings (Ashforth \& Humphrey, 1993; Grandey, 2003; Hochschild, 1979, 1983). This can lead to emotional dissonance during the inner-outer interaction (Zapf, 2002). Employees adopting the DA strategy attempt to modify their inner feelings to manage their displayed emotions and match display rules (Ashforth \& Humphrey, 1993; Grandey, 2003) by focusing on positive aspects of a situation.

\section{Job Satisfaction}

A general sense of $J S$ refers to an attitude or view of the work itself and the related environment. It may involve employees' satisfaction with work status, work pattern, work stress, and interpersonal relationships in the workplace. Smith and Wakeley (1972) pointed out that JS is an average emotional state caused by good or bad emotional experiences at work. Locke (1973) further emphasized that JS is a pleasant emotional state, which is the result of the appraisal of one's job or job experience. Companies value JS because it reflects 'employees' reactions to what they receive" (Wright, 2001, p. 562) and may beneficially influence their further effort and performance.

\section{Job Characteristics}

According to Herzberg, Mausner, and Snyderman's (1959) two-factor theory, job characteristics can be classified into two categories: the hygiene factor (i.e., job context) relating to company policy and objective work conditions, and the motivation factor (i.e., job content) relating to a sense of achievement and 
responsibility. Turner and Lawrence (1965) identified five job characteristics influencing employees' JS and performance: skill diversity (SD), job autonomy (JA), selective social interaction, knowledge and skills, and responsibility. Wright and Davis (2003) also found four job characteristics (i.e., job routines [JR], job goal specificity, feedback, and human resource development) that can impact on JS. From these characteristics, we adopted JR, JA, and SD.

\section{Hypotheses}

In line with the ELS theory, employees who display their true emotions without reluctance and pretense, are more likely to enjoy their work. Previous researchers have established a relationship between ELS and JS. For example, Grandey (2000) found that JS was negatively correlated with the SA strategy and positively correlated with the DA strategy. SA decreases employees' JS because it suppresses people's real emotions (Hochschild, 1983; Van Maanen \& Kunda, 1989). DA increases JS because it can promote a personal sense of accomplishment (Brotheridge \& Lee, 2002). Thus, we proposed the following:

Hypothesis 1: Surface acting will negatively impact on job satisfaction.

Hypothesis 2: Deep acting will positively impact on job satisfaction.

Wharton (1993) stated that the relationship between ELS and JS may be moderated by job characteristics because they may promote or prevent employees' willingness to use ELS. These job characteristics may or may not meet different employees' needs (Hackman \& Oldham, 1976), which may subsequently affect their JS. Employees may also have a differential view on skill diversity, or place different importance on JR and JA. These differences may influence employees' reactions to ELS. For example, Morris and Feldman (1996) pointed out that in the process of using ELS, employees with greater JA experience less psychological oppression, thus increasing the level of JS. Thus, we proposed the following hypotheses:

Hypothesis 3: Job routines will moderate the relationship between emotional labor strategy and job satisfaction.

Hypothesis 4: Job autonomy will moderate the relationship between emotional labor strategy and job satisfaction.

Hypothesis 5: Skill diversity will moderate the relationship between emotional labor strategy and job satisfaction.

\section{Method}

\section{Participants}

Participants were 291 employees (response rate $=90.9 \%$ ) who worked in nine large supermarkets in three cities in mainland China. Of the participants, $73.2 \%$ were women and $26.8 \%$ were men, with an average age of 39 years and an average work experience of 3.2 years. 


\section{Measures}

SA was measured using four items of Diefendorff, Croyle, and Gosserand's (2005) 7-item scale. A sample item is "I just pretend to have the emotions I need to display for my job". DA was measured using all four items in the relevant scale from this same instrument. A sample item is "I make an effort to actually feel the emotions that I need to display toward others". Participants rated each item using a 7-point Likert scale ranging from $1=$ strongly disagree to $7=$ strongly agree. Reliabilities for SA and DA were .88 and .84 , respectively. Each job characteristic, that is, JR, JA, and SD, was measured by four items developed by Morris and Feldman (1996). Reliabilities for JR, JA, and SD were .81, .81, and .87, respectively. JS was measured using Smith, Kendall, and Hulin's (1969) 9-item scale. Gender, age, and work experience were controlled in the data analysis. All items (except control variables) were responded to on a 5-point Likert scale ranging from $1=$ strongly disagree to $5=$ strongly agree. Reliability for this scale was .95 .

\section{Results}

On the basis of a two-tailed test, the correlation between SA and JS was negative and significant, and the correlation between DA and JS was positive and nonsignificant. We then conducted a regression analysis (incorporating both SA and DA) with a one-tailed test. Results showed the regression coefficients of SA $(\beta=-.62, p<.001)$ and DA $(\beta=.09, p<.05)$ were all significant. Thus, Hypothesis 1 and Hypothesis 2 were supported.

To test the moderating effects of job characteristics on the relationships between JS and both SA and DA, a series of three-step hierarchical regression analyses were performed separately for each moderator. Gender, age, and work experience were entered first. SA, DA, and one of the moderating variables were entered in the second step. The interaction terms (the cross-product of the moderating variable with SA and DA separately) were entered last. The moderating effects would be confirmed if the interaction terms were statistically significant. Results showed that both JR and JA moderate the relationships of JS with SA ( $\beta=.13, p$ $<.01 ; \beta=-.21, p<.001)$, and with DA $(\beta=.10, p<.05 ; \beta=-.12, p<.01)$. SD was found to moderate the relationship between SA and JS $(\beta=.15, p<.01)$, but not that between DA and JS $(\beta=-.02, n s)$.

\section{Discussion and Conclusion}

In this study, we examined how employees' emotional labor strategies influence their job satisfaction, and how job characteristics moderate these influences. Hypothesis 3 and 4 were fully supported, and Hypothesis 5 was partially supported. Overall, the results in our study produced meaningful findings. 
First, although SA had a negative effect on JS, DA had a positive effect on JS. The results verify Grandey's (2000) theoretical model and are consistent with Van Maanen \& Kunda's (1989) and Brotheridge \& Lee's (2002) findings. Our findings suggest that employees who use SA may have to suppress their true feelings to comply with organizational display rules. This leads to a reduced level of JS. Because employees using DA are able to maintain a consistency between their true feelings and display rules, this is helpful in improving their JS. In comparison with employees using the SA strategy, they may experience less emotional exhaustion.

Second, job characteristics, in general, moderated the relationship between ELS and JS. According to our findings, a lower level of JR may be helpful in improving JS among employees who adopt the SA strategy, and the reverse is true for those who adopt the DA strategy. In a low JA situation, employees who adopted the SA strategy were more dissatisfied with their jobs than those who adopt the DA strategy. They tended to be more satisfied with their jobs. In addition, employees preferring SA were more likely to have higher JS when their position required a low level of SD. In contrast, it appears that SD does not affect the JS of employees who prefer DA.

Our empirical findings generated from the Chinese supermarket industry suggest that managers should deal with supermarket service employees according to their ELS preference. When designing positions, supermarket managers can be encouraged to consider the levels of JR, JA, and SD for work positions in conjunction with ELS. In particular, organizations should employ effective measures to help employees who prefer SA to improve their levels of JS. For example, allowing employees to work more autonomously, endeavoring to reduce job routineness when designing a position, and considering allocating these employees relatively simple tasks, which require less diverse skills.

There are several limitations in this study. First, the data were obtained from a single source of supermarket employees and this may have resulted in common method bias. Future researchers could use data from different sources, for example, taking into account both data reported by employees and rated by supervisors. Second, we investigated employees' job satisfaction in a specific time and did not explore their change of job satisfaction as job characteristics vary. Future researchers may employ longitudinal methods to examine whether or not SA-oriented employees can significantly improve their level of JS when job characteristics change. In addition, future researchers can investigate the relationship of emotion-related characteristics with other work behaviors and attitudes in different contexts.

\section{References}

Ashforth, B. E., \& Humphrey, R. H. (1993). Emotional labor in service roles: The influence of identity. Academy of Management Review, 18, 88-115. http://doi.org/df4qpz 
Brotheridge, C. M., \& Lee, R. T. (2002). Testing a conservation of resources model of the dynamics of emotional labor. Journal of Occupational Health Psychology, 7, 57-67. http://doi.org/fr7nh5

Diefendorff, J. M., Croyle, M. H., \& Gosserand, R. H. (2005). The dimensionality and antecedents of emotional labor strategies. Journal of Vocational Behavior, 66, 339-357. http://doi.org/czn

Grandey, A. A. (2000). Emotional regulation in the workplace: A new way to conceptualize emotional labor. Journal of Occupational Health Psychology, 5, 95-110. http://doi.org/fhfzhc

Grandey, A. A. (2003). When "the show must go on": Surface acting and deep acting as determinants of emotional exhaustion and peer-rated service delivery. Academy of Management Journal, 46, 86-96. http://doi.org/cbz6gz

Hackman, J. R., \& Oldham, G. R. (1976). Motivation through the design of work: Test of a theory. Organizational Behavior and Human Performance, 16, 250-279. http://doi.org/hbs

Herzberg, F., Mausner, B., \& Snyderman, B. B. (1959). The motivation to work (2nd ed.). New York: Wiley.

Hochschild, A. R. (1979). Emotion work, feeling rules, and social structure. American Journal of Sociology, 85, 551-575.

Hochschild, A. R. (1983). The managed heart: Commercialization of human feeling. Berkeley, CA: University of California Press.

Locke, E. A. (1973). Satisfiers and dissatisfiers among white-collar and blue-collar employees. Journal of Applied Psychology, 58, 67-76. http://doi.org/cpzcvk

Morris, J. A., \& Feldman, D. C. (1996). The dimensions, antecedents, and consequences of emotional labor. Academy of Management Review, 21, 986-1010. http://doi.org/fxbjt6

Rafaeli, A., \& Sutton, R. I. (1987). Expression of emotion as part of the work role. Academy of Management Review, 12, 23-37. http://doi.org/fq22dj

Rainey, H. G. (2009). Understanding and managing public organizations (4th ed.). San Francisco, CA: Jossey-Bass.

Smith, H. C., \& Wakeley, J. H. (1972). Psychology of industrial behavior (3rd ed.). New York: McGraw-Hill.

Smith, P. C., Kendall, L. M., \& Hulin, C. L. (1969). The measurement of satisfaction in work and retirement: A strategy for the study of attitudes. Chicago, IL: Rand McNally.

Turner, A. N., \& Lawrence, P. R. (1965). Industrial jobs and the worker: An investigation of response to task attributes. Boston, MA: Harvard University, Division of Research, Graduate School of Business Administration.

Van Maanen, J., \& Kunda, G. (1989). Real feelings: Emotional expression and organizational culture. In L. L. Cummings \& B. M. Staw (Eds.), Research in organizational behavior (Vol. 11, pp. 43-103). Greenwich, CT: JAI Press.

Wharton, A. S. (1993). The affective consequences of service work: Managing emotions on the job. Work and Occupations, 20, 205-232. http://doi.org/ddssvt

Wharton, A. S., \& Erickson, R. J. (1993). Managing emotions on the job and at home: Understanding the consequences of multiple emotional roles. Academy of Management Review, 18, 457-486. http://doi.org/ftj3g8

Wright, B. E. (2001). Public-sector work motivation: A review of the current literature and a revised conceptual model. Journal of Public Administration Research and Theory, 11, 559-586.

Wright, B. E., \& Davis, B. S. (2003). Job satisfaction in the public sector: The role of the work environment. The American Review of Public Administration, 33, 70-90. http://doi.org/bdbvp4

Zapf, D. (2002). Emotion work and psychological well-being: A review of the literature and some conceptual considerations. Human Resource Management Review, 12, 237-268. http://doi.org/ gt3 
Reproduced with permission of the copyright owner. Further reproduction prohibited without permission. 